\title{
A EXPERIÊNCIA DE FALAR SOBRE AS RELIGIÕES AFRO-BRASILEIRAS...
}

\author{
Ariadne Moreira Basílioº
}

Esse texto faz parte das reflexões que embasaram a construção da minha dissertação sobre racismo religioso e as religiões afro-brasileiras. Tem o intuito de dizer um pouco da minha trajetória acadêmica como filha de santo e pesquisadora de um tema imerso na grandeza e complexidade dessas religiões que são, na verdade, portadoras de modos de vida que se distinguem da sociabilidade ocidental.

O meu tema de mestrado, ou seja, o tema que escolhi para pesquisar durante o percurso do meu mestrado nunca mudou. Independentemente das circunstâncias que se arrolavam no momento em que entrei no Programa de Pós-Graduação em Direitos Humanos e Cidadania na Universidade de Brasília e de questões pessoais que vivi, meu foco foi inabalado.

Contudo, foram muitas as dificuldades que encontrei como pesquisadora nesse percurso que envolveu as relações entre sujeito-sujeitos, entre pesquisadora e sujeitos da pesquisa. Também foram muitas as dificuldades de tratar do tema tendo poucos professores e professoras que se interessam pelo mesmo e à mercê de uma bibliografia principalmente os trabalhos que iniciaram a discussão sobre as religiões afro-brasileiras, como Raimundo Nina Rodrigues e Arthur Ramos - que, entre outras contribuições, não deixou de explicitar as formas racistas como compreendia a afrorreligiosidade.

Não houve uma trajetória linear na construção da minha dissertação, assim como não houve uma linearidade na definição do foco a ser dado na mesma. Os caminhos foram tortuosos e, em alguns momentos, mais que uma pretensa visualização, pude sentir as dificuldades e os obstáculos impostos pelo tema. Afinal, falar das religiões afro-brasileiras, para além do modismo e exotismo ${ }^{3}$ que parece cercar o tema - assim

\footnotetext{
${ }^{1}$ O presente trabalho foi realizado com apoio da CAPES - Coordenação de Aperfeiçoamento de Pessoal de Nível Superior.

2 Mestranda em Direitos Humanos pela Universidade de Brasília, orientada pela Professora Dra. Rita Laura Segato. Integrante do Calundu - Grupo de Estudos sobre Religiões Afro-Brasileiras.

${ }^{3}$ No mundo acadêmico o tema ainda não deixou de ser exotizado, ainda resquício de uma antropologia que o trata como alternativas primitivas de formas de organização dos povos não ocidentais e tendo os ocidentais como um fim na sua escalada evolucionista, que culmina com o auge civilizacional das sociedades do norte global.
} 
como tem se apresentado a decolonialidade - é, para mim, uma questão de ética, política e vivência, na medida em que não me coloco como uma pesquisadora neutra e distanciada de meu "objeto", na busca da tão afamada estrutura ocidental de se fazer ciência. Meu engajamento político e minha atuação no chamado "campo" foram os determinantes da minha escolha. Fazem do meu olhar, como ensina Donna Haraway (1995), situado.

Trocando em miúdos, as religiões afro-brasileiras sempre estiveram como tema de meu interesse, dentre outros motivos, pelo mais óbvio que é a minha condição de filha de santo, que me compele a uma necessidade política de visibilidade do tema, desde minha entrada no mestrado da Universidade de Brasília.

Sou candomblecista, filha de orixá. Na minha cabeça, no meu peito, no meu corpo, habitam as forças da natureza. Não sou apartada do meu tema por uma imposição acadêmica. O meu lugar é nominado e deve ser enunciado, não como sinal de fraqueza teórica, mas sim como comprometimento político e social. Isso não faz com que meu trabalho seja menos válido, e sim mais honesto.

Inicialmente construí uma problematização em torno do ensino religioso obrigatório em escolas públicas e a dificuldade da expressão religiosa das crianças e adolescentes adeptos das religiões afro-brasileiras nesse contexto. Entretanto, foi a partir da sequência de ataques a terreiros de candomblé no Distrito Federal e entorno ${ }^{4}$, no ano de 2015, que fixei meu tema na (des)relação social mascarada como intolerância religiosa.

Os casos descritos como intolerância religiosa que ocorreram em 2015, no Distrito Federal e entorno, me despertaram a raiva, a indignação, o interesse ainda maior para escrever sobre o tema e a urgência política do mesmo. Isso porque estive imbricada nesses processos pessoalmente.

A série de ataques me despertou vários sentimentos como indignação, tristeza, raiva, revolta e uma curiosidade para entender como essas violações tinham acontecido. A casa em que fui iniciada sofreu um ataque, assim como a casa da minha madrinha de orunk $o^{5}$. Novamente, a importância do debate tornou-se impostergável. É preciso falar

\footnotetext{
4 "Região Integrada de Desenvolvimento do Distrito Federal e Entorno", microrregião reconhecida pela Lei Complementar n. 94, de 19 de fevereiro de 1998, e regulamentada pelo Decreto n. 2.710, de 4 de agosto de 1998 (BRAŚ́LIA, 1998), e alterações posteriores. A designação "entorno" é dotada de sentido geopolítico e remete ao espaço limítrofe entre o Distrito Federal e o Estado de Goiás.

${ }^{5}$ Faz parte de um dos rituais de iniciação a cerimônia em que há o anúncio do nome de santo - orunkó, e para conduzir a cerimônia é escolhida uma madrinha ou um padrinho para este momento.
} 
das violações que as religiões afro-brasileiras têm sofrido ao longo dos anos. Elas não podem ser esquecidas em nenhum momento.

Sim, as religiões afro-brasileiras vêm sofrendo violações ao longo dos anos de sua existência, assim como as práticas dos povos africanos ressignificadas e reproduzidas em terras brasileiras. Apesar da série de ataques evidenciada no ano de 2015 pela mídia, sobre os casos que ocorreram no Distrito Federal e entorno, esses não foram os primeiros e infelizmente não parece que serão os últimos.

Quando fui estudar sobre a intolerância religiosa, ao pesquisar, conversar sobre, vi que a categoria "intolerância religiosa" não daria conta do fenômeno, pois as suas causas e as consequências que envolvem omissões institucionais e falta de políticas específicas para essas comunidades, referem-se a uma prática, ou melhor, uma estrutura racista das instituições estatais e da sociedade brasileira.

A dificuldade sobre a bibliografia a ser utilizada para se desenvolver tal perspectiva retorna ainda com mais força e se soma à invisibilização da questão do racismo na sociedade brasileira.

No Brasil, apesar da existência da Lei Caó (Lei 7.716/89) (BRASIL, 1989), que tipifica como crime o racismo em suas variadas formas, uma série de pesquisas e mesmo dados jurídicos apontam para o fato de que são raros os casos em que as discriminações raciais tramitam enquadradas na referida lei ${ }^{6}$. Em sua grande maioria, os casos de racismo são enquadrados como "injúria racial"”, o que diminui, por fim, a estrutura do racismo a uma ofensa individualizada, descaracterizando a estrutura racista que envolve toda a sociedade.

Não há como fazer um trabalho sobre as maravilhas comunitárias que desafiam o projeto ocidental de desenvolvimento e modernidade, sem dizer que exatamente por isso essas comunidades sofrem tentativas de destruição diárias com violências racistas simbólicas e físicas.

O tema "religiões afro-brasileiras" tem um efeito. Alguns dizem que está na moda. O fato é que, estando na moda ou não, no mundo real, comunidades de terreiro sofrem com as violências impetradas pelo Estado e pela parcela da sociedade que se

\footnotetext{
${ }^{6}$ Para detalhes ver livro "Direitos Humanos e as Práticas de Racismo", de Ivair Santos (2013).

7 A injúria é tipificada como crime no artigo 140, parágrafo $3^{\circ}$, do Código Penal brasileiro (BRASIL, 1940). Refere-se a ofensas raciais dirigidas sempre de um indivíduo a outro, ao passo que a Lei Caó define crime de racismo como ofensa contra toda uma coletividade. Por exemplo, se alguém disser que uma pessoa negra é desqualificada para algo em função de sua cor, a compreensão é a de que a ofensa é a todos os negros.
} 
quer ver como herdeira da branquitude e de seus ideais morais cristãos. A realidade é que as tentativas de tradução dessas comunidades em termos acadêmicos ocidentais modernos não são possíveis. Trata-se de outra coisa, de outros modos, outra compreensão.

Trazer o conhecimento e a sabedoria dessas comunidades para a academia, um ambiente em que a produtividade científica está baseada na replicação do que autores do norte global disseram sobre os nossos corpos e nossas vidas, é um enorme desafio.

Dentro de uma racionalidade que produz conhecimentos de forma binária, não é possível se falar do tema das religiões afro-brasileiras sem recair em problemas de simplificação e incompreensão do tema. É necessária uma outra abordagem.

Propus-me a este desafio em meu mestrado e não o enfrentei sem pagar o preço da dificuldade e da angústia relacionada, pois, apesar do giro decolonial e da construção de uma perspectiva que preze pelo reconhecimento de outros saberes, ainda há muito a ser transformado na academia para ser um ambiente que não só utilize de forma apropriadora as formas de produção e transmissão de conhecimento das religiões afrobrasileiras, mas que se abra para a forja de uma gira epistêmica!

\section{Referências}

BRASIL. Decreto-Lei 2.848, de 07 de dezembro de 1940. In: Diário Oficial da União. Rio de Janeiro: DOU, 1940.

BRASIL. Lei no 7.716 de 05 de janeiro de 1989. In: Diário Oficial da União. Brasília: DOU, 1989.

BRASÍLIA. Decreto 2.710 de 04 de agosto de 1998. In: Diário Oficial do Distrito Federal. Brasília: DOU, 1998.

HARAWAY, Donna. "Saberes Localizados: a questão da ciência para o feminismo e o privilégio da perspectiva parcial”. In: Cadernos Pagu (5) 1995: pp. 07-41.

SANTOS, Ivair Augusto Alves dos. Direitos Humanos e as Práticas de Racismo. Brasília: Câmara dos Deputados, Edições Câmara, 2013. 
Revista Calundu - vol. 1, n.1, jan-jun 2017

Direitos Humanos e as Práticas de racismo: o que faremos com os brancos racistas. 2009. 514f. Tese (Doutorado em Sociologia) - Departamento de Sociologia, Universidade de Brasília, Brasília, 2009. 